\title{
Aprendizagem de línguas in-tandem: um suporte inovador na aprendizagem de língua inglesa
}

\author{
Edi Marli da Silva NUNES \\ FUNEC - Santa Fé do Sul ${ }^{1}$ \\ edimarli@hotmail.com \\ Wiliam César RAMOS ${ }^{2}$ \\ UNEMAT - Alto Araguaia \\ wiliamramos@yahoo.com.br
}

\section{Resumo}

As novas tecnologias têm estabelecido um novo cenário para a educação convencional, inserindo o computador e a Internet como elementos de aprimoramento da aprendizagem de línguas. O ambiente de aprendizagem de línguas in-tandem insere-se nesse contexto. $\mathrm{O}$ presente artigo tem como objetivo demonstrar que esse ambiente de aprendizagem pode complementar a aula de inglês convencional. Para isso, analisamos três sessões in-tandem, realizadas a distância por meio do aplicativo msn messenger entre um participante brasileiro e outro mexicano, com base nas descrições de aprendizagem de línguas in-tandem. Os resultados indicam que esse ambiente de aprendizagem pode contribuir para a aprendizagem de língua estrangeira em aulas convencionais do Ensino Médio.

Palavras-chave: aprendizagem in-tandem; novas tecnologias; aprendizagem de línguas; escola pública.

\footnotetext{
Abstract

New technologies have established a new background for traditional education. Among them are the computer and the Internet which can help improve second language learning. The tandem language learning environment is part of this new context. The objective of this work is to

${ }^{1}$ Fundação Municipal de Educação e Cultura de Santa Fé do Sul

${ }^{2}$ A primeira versão deste artigo foi produzida enquanto o autor era bolsista FAPESP (01/03/2010 a 31/05/2011).
} 
demonstrate that tandem learning can complement traditional language classes. In order to do that we analyzed three tandem sessions performed at a distance through the chat software MSN Messenger between a Brazilian and a Mexican participant. The analysis was based on descriptions of tandem language learning. The results show that this learning environment can improve foreign language learning in traditional high school classes.

Keywords: tandem learning; new technologies; language learning; public school.

\section{Introdução}

As novas tecnologias vêm sendo utilizadas como recursos de aprendizagem e têm ocasionado mudanças significativas nas mais diversas áreas da educação, como, por exemplo, no ensino de língua estrangeira. Dentre essas tecnologias, o computador e a Internet destacam-se, pois tornam o ensino mais atrativo e inovador, inserindo alunos e professores no mundo globalizado (PAIS, 2005).

$\mathrm{O}$ ambiente de aprendizagem de línguas in-tandem, que na modalidade eletrônica envolve o uso do computador conectado à Internet, situa-se nesse contexto inovador da educação. A aprendizagem de línguas in-tandem compreende um ambiente de aprendizagem que é caracterizado pela interação colaborativa entre dois participantes com objetivos semelhantes, isto é, um aprender a língua materna do outro, ou uma língua em que o outro é proficiente, numa ajuda mútua que torna a aprendizagem mais dinâmica e estimulante (BRAGA, 2004).

Nas interações in-tandem, um participante assiste o outro, corrigindo, sugerindo formas alternativas, traduzindo e explicando significados; eles não ensinam, mas ajudam o outro a aprender, respeitando seus limites e expectativas. Além disso, respeitam o método de aprendizagem do parceiro, mesmo que lhe pareça ineficiente, estabelecendo uma situação de reciprocidade em que um procura auxiliar o outro, obedecendo às estratégias de aprendizagem do parceiro, podendo adotá-las para si ou não. Existem três tipos de tandem: o teletandem, em que as interações ocorrem por meio dos programas de mensagens instantâneas (msn messenger, skype, etc.); o 
tandem face a face, cujas interações são presenciais; e o $e$-tandem, que consiste na troca de $e$-mails via correio eletrônico.

Portanto, tendo em vista que o ambiente de aprendizagem intandem permite uma aprendizagem diferente daquela proporcionada pela aula tradicional, em que, salvo as raras exceções, os assuntos abordados são determinados pelo material didático adotado e não há situações reais de comunicação para a prática do idioma, este artigo analisa uma experiência com interações in-tandem entre um participante brasileiro e um participante mexicano, de modo a destacar as contribuições que essa modalidade de aprendizagem pode trazer para as práticas pedagógicas convencionais de um importante estágio do Sistema Educacional Brasileiro: o Ensino Médio.

\section{As novas tecnologias no ensino de língua estrangeira}

Segundo Martins (2005, p. 63), “a escola, quando orientada por princípios inovadores, dará outro rumo aos métodos de ensino e aprendizagem." Com a chegada das novas tecnologias, a escola tradicional encontra-se em um período de transição entre velhas e novas práticas, portanto irá deparar-se com os desafios de desenvolver projetos pedagógicos que contemplem as inovações tecnológicas e de assumir posturas que promovam a interatividade entre alunos, com oportunidade de abandonar modelos de ensino que se tornaram desestimulantes e que não acompanharam as transformações da sociedade.

Por pertencer a uma era transformada pelas novas tecnologias, o aluno de hoje necessita de uma escola que atenda suas necessidades. O professor, que tem assumido um papel controlador na administração da dinâmica da aula, assumirá outras funções, tais como orientar os alunos no seu processo de aprendizagem que, agora, será complementado por recursos tecnológicos. Dentre outras inovações, esses recursos permitirão que os alunos frequentem ambientes virtuais, onde terão autonomia em sua experiência de aprendizagem (MARTINS, 2005).

A Internet será utilizada para a comunicação virtual entre professores e alunos para compartilhar informações e interagir com falantes de outros países, permitindo o aprimoramento dos 
conhecimentos adquiridos em sala de aula e o acesso à cultura de outros povos. Os livros didáticos não mais se constituirão o único ou principal material didático, mas uma fonte de consulta (MORAN; MASETTO; BEHRENS, 2000). A escola do futuro, assim chamada pelos incentivadores da inovação educacional, necessitará de professores flexíveis em suas práticas docentes para incorporar as mudanças oriundas do cenário tecnológico que vem se estabelecendo gradativamente, mas ao mesmo tempo serão críticos para fazê-lo de modo a trazer benefícios, ao invés de prejuízos, à experiência do ensinar e do aprender.

A escola do futuro é aquela que reconhece que nem ela, nem o professor, nem os livros são as únicas fontes do conhecimento, mas que o conhecimento pode estar também nas infinitas informações que nos inundam a cada instante, sendo, portanto, indispensável ensinar a filtrá-las e transformá-las em saber; que o conhecimento pode, também, esconder-se nas coisas simples do cotidiano, mas que para reconhecê-lo será preciso ter competência para refletir sobre essas coisas e analisá-las dando-lhes sentido (MARTINS, 2005, p.70).

As novas tecnologias vêm sendo utilizadas como suporte ao processo de aprendizagem e têm produzido mudanças em diferentes contextos educacionais, principalmente, na área de ensino de línguas estrangeiras (PAIS, 2005). Dentre essas mudanças, destaca-se a utilização de computadores e internet no Ensino Público, que possibilita aos alunos novas formas de comunicação com o mundo e, consequentemente, com falantes nativos e outros aprendizes da língua estrangeira ensinada na escola (ALMEIDA; FONSECA JUNIOR, 2000). O emprego dessas ferramentas tecnológicas visa à inovação do ensino, tornando-o mais envolvente e produtivo: "a informática trará novas possibilidades, resultando em uma aprendizagem mais eficiente, mais profunda, mais confortável, mais feliz.” ( p.67).

Dentro desse movimento de inovação educativa, a inovação não pode ser vista como reforma porque ela não visa a renovar práticas ineficientes, mas a descobrir novas práticas que, estando em sintonia com a evolução da sociedade em todos os seus aspectos, contribuam para a melhoria da qualidade da educação. Entretanto, novas práticas 
não podem substituir velhas práticas repentinamente, pois exige um planejamento cuidadoso e que demanda, principalmente, tempo porque "sabe-se que a mudança é um longo processo e que é preciso pensar globalmente e atuar localmente, isto é, passo a passo" (CARBONELL, 2002, p.24). Portanto, a inovação educativa requer empenho, esforço e flexibilidade de todos os envolvidos no processo de ensinoaprendizagem, gerando, assim, resultados significativos tanto para o docente quanto para o aluno que, nesse processo, é o principal elemento.

\section{A aprendizagem de línguas in-tandem}

$\mathrm{O}$ ambiente de aprendizagem in-tandem insere-se no contexto da inovação educativa e permite a interação entre dois indivíduos, em que ambos se beneficiam e cooperam com a aprendizagem um do outro. Nesse ambiente colaborativo, cada participante deve preparar-se para as sessões, elaborando, por exemplo, um roteiro de tópicos a serem discutidos ou explicações gramaticais, para que tenha condições de sanar possíveis dúvidas de seu parceiro (BRAGA, 2004).

Para que a aprendizagem seja concretizada, é preciso que haja a manutenção dos três pilares de sustentação do tandem, a saber: a reciprocidade, o bilinguismo e a autonomia. No princípio da reciprocidade, cada aprendiz deve beneficiar-se igualmente da parceria, tendo a expectativa tanto de receber como de oferecer ajuda. Há a necessidade de envolvimento e compromisso de ambas as partes, atentando para as necessidades um do outro.

O princípio do bilinguismo consiste no comprometimento de cada participante em usar, nas interações, ambas as línguas em proporções iguais. Isso significa que numa atividade envolvendo tandem onde um participante venezuelano ensina espanhol para um participante americano que, por sua vez, ensina inglês ao participante venezuelano, tanto o idioma espanhol como o idioma inglês devem ser empregados nos diálogos, sejam presenciais ou a distância, em proporções iguais, de modo que ambos os participantes possam exercitar a língua que desejam aprender.

$\mathrm{O}$ princípio da autonomia refere-se à responsabilidade que cada participante assume pela sua própria aprendizagem, determinando 
como e quando quer aprender, assim como que tipo de ajuda (correções de pronúncia, ortografia, sintaxe, vocabulário, etc.) gostaria de receber de seu parceiro (BRAMMERTS, 2003; LITTLE, 2003).

Nas interações in-tandem podem ser abordados assuntos diversos sobre aspectos culturais, experiências de vida, assuntos cotidianos e até mesmo tópicos gramaticais. Há três modalidades de tandem: a) o tandem face a face, que consiste na interação presencial dos participantes que utilizam a oralidade para suas interações, e, às vezes, a escrita para fazer anotações sobre dúvidas não esclarecidas ou tópicos para as próximas sessões; b) o e-tandem, que compreende a troca de e-mails via correio eletrônico; e c) o teletandem, realizado por meio de aplicativos de mensagens instantâneas (msn messeger, skype, etc.) (RAMOS; BARBOSA, 2009).

O tandem face a face e o teletandem são tandem síncronos, pois as interações acontecem em tempo real. Já o e-tandem é assíncrono, visto que os e-mails podem ser lidos ou respondidos horas ou dias depois de terem sido escritos e enviados. Em qualquer dessas modalidades, os participantes acordam em que desejam ser corrigidos (pronúncia, gramática, vocabulário), com que frequência (a cada erro, apenas quando não se faz entender ou somente quando for solicitada a ajuda) e que tipo de ajuda esperam do parceiro (intervenções durante ou após a interação, repetições, explicações gramaticais, ajuda na falta de vocabulário, etc.).

O teletandem, modalidade síncrona do tandem, apresenta vantagens com relação ao $e$-tandem, também síncrono, porque permite o uso de recursos de áudio, vídeo e lousa, que auxiliam os participantes na solução de dúvidas, pois podem beneficiar-se de mímicas, expressões faciais, entoações de voz, desenhos e escrita. Outra vantagem é a conveniência de não ter que se deslocar do seu local de estudo, seja sua residência ou escola, para realizar as interações.

Como podemos observar, o ambiente de aprendizagem intandem permite uma aprendizagem diferente da realizada em sala de aula tradicional e complementar a ela. $\mathrm{O}$ aluno passa a ser sujeito ativo em sua formação, desenvolvendo seus conhecimentos no mesmo ambiente em que vive, alcançando, assim, uma formação resultante da combinação entre teoria (descrições gramaticais e lexicais) e prática (interações por e-mails e diálogos) ligada à experiência e em contato 
direto com a língua que se deseja aperfeiçoar (RAMOS; BARBOSA, 2009).

\subsection{O tandem institucionalizado}

O tandem institucionalizado é vinculado a uma instituição de ensino e, portanto, possui um mediador que pode ser um professor de línguas ou alguém com experiência em aprendizagem in-tandem ou ensino de línguas. O papel do mediador é assistir os alunos participantes do tandem em não perderem de vista questões importantes sobre a preparação para as sessões e a colaboração com a aprendizagem do parceiro, além de poder, ocasionalmente, sanar dúvidas sobre questões gramaticais.

Um exemplo de tandem institucionalizado é o realizado pela Universidade do Estado de Mato Grosso (UNEMAT), no campus de Alto Araguaia, em parceria com uma universidade americana do estado de Minnesota, a University of Minnesota (UNEMAT, 2011). A UNEMAT dispõe de um moderno laboratório de informática equipado com computadores, webcams e Internet, infraestrutura necessária para oferecer o ambiente de aprendizagem in-tandem aos alunos da instituição. $\mathrm{O}$ projeto denominado Aprendendo $e$ Ensinando em Prática de Tandem via Chat (UNEMAT, 2009) é coordenado pela professora Ana Carolina de Laurentiis Brandrão, que é encarregada de divulgar essa modalidade de aprendizagem aos alunos da universidade, principalmente aos do curso de Letras, realizar reuniões para esclarecer dúvidas, preparar os alunos interessados em aderir ao projeto e exercer o papel de mediadora com outros mediadores, dando assistência linguística e pedagógica aos participantes quando a mediação se faz necessária. As interações são realizadas no laboratório de informática, entre alunos da UNEMAT e da universidade americana, em horários pré-estabelecidos de acordo com o fuso-horário entre o Brasil e os Estados Unidos. As línguas utilizadas para a comunicação são o português, o inglês e o espanhol, de acordo com o nível de proficiência no idioma e com as necessidades dos participantes brasileiros e americanos.

Há também o tandem não institucionalizado que não é vinculado a nenhuma instituição de ensino, mas realizado por pessoas, matriculadas ou não em algum tipo de instituição de ensino, 
interessadas em aprender ou aprimorar seus conhecimentos de uma língua estrangeira, modalidade em que não há a presença de um mediador. Nesses casos, o indivíduo pode encontrar parceiros para o tandem em sites de acesso gratuito com essa finalidade, como o www.tandemserver.com, por exemplo.

\subsection{O papel do mediador}

$\mathrm{O}$ ambiente de aprendizagem in-tandem diferencia-se da aula convencional, também pelo papel do professor que, ao invés de controlar o que será ensinado, assume o papel de mediador. O papel do professor mediador não é impor métodos, conteúdos ou limites, mas agir como conselheiro auxiliando o aluno participante do tandem a estar atento para questões importantes na manutenção da parceria, tais como seleção de tópicos a serem abordados nas interações, formas de ajudar o parceiro a aprender e, até mesmo, estratégias de ensino e aprendizagem. Posicionando-se como mediador, o professor pode perceber as necessidades do(s) aluno(s) e interceder no sentido de garantir o sucesso da aprendizagem (RAMOS; BARBOSA, 2009).

$O$ papel do professor numa aula convencional de língua estrangeira pode variar de acordo com o método adotado. No Método Audiolingual, o professor serve como modelo para o aluno, produzindo estruturas gramaticais e pronúncias corretas. Seu papel é levar o aluno a comunicar-se na língua-alvo por meio de condicionamento e formação de hábitos linguísticos corretos. No Método Direto, o professor seleciona o conteúdo a ser apresentado aos alunos, auxiliando-os por meio de mímicas, figuras ou objetos. Na Abordagem Comunicativa, o professor deixa de exercer um papel centralizador e assume o papel de facilitador, criando situações comunicativas que levem os alunos a praticarem o idioma. Nessa abordagem, há uma participação mais ativa do aluno (LARSEN-FREEMAN, 2004).

Nas três situações, o professor desempenha, em maior ou menor grau, um papel de controlador da aprendizagem deixando os alunos com pouca autonomia sobre o processo de aprendizagem. No ambiente de aprendizagem de línguas in-tandem, há o mediador que não seleciona o conteúdo a ser abordado nem controla a aprendizagem do participante, mas o assiste nesse processo. 
O papel do mediador é, portanto, o de ajudar os participantes a desenvolverem sua autonomia de aprendizagem, não impondo métodos ou teorias, mas, fazendo bom uso de seu conhecimento em linguística aplicada ao ensino de línguas, apresentar ao participante questões relevantes nas tomadas de decisões no que se refere a estratégias de aprendizagem, ao planejamento das sessões e à assistência ao parceiro (RAMOS; BARBOSA, 2009, p.188).

\section{Metodologia}

Para demonstrarmos que o ambiente de aprendizagem de línguas in-tandem pode complementar a aula convencional de língua estrangeira, convidamos um participante brasileiro, de dezesseis anos de idade, que cursa o $3^{\circ}$ ano do Ensino Médio da Rede Pública no interior do estado de São Paulo, e que tem seu conhecimento de inglês proveniente apenas do Ensino Público, para participar da pesquisa relatada neste artigo. Primeiramente, explicamos ao participante os princípios do tandem da reciprocidade, do bilinguismo e da autonomia. Ele foi instruído sobre como colaborar com o parceiro na sua aprendizagem e como beneficiar-se das interações para aprender uma segunda ${ }^{3}$ língua, o inglês. Em seguida, fornecemos endereços de sites de tandem, onde os interessados de qualquer faixa etária se cadastram para encontrar um parceiro. Os sites apresentados foram www.sharedtalk.com, www.livemocha.com e www.tandemserver.com. Por meio do site www.sharedtalk.com, o participante brasileiro, interessado em aprimorar seus conhecimentos em inglês e disposto a ensinar português, encontrou um participante mexicano de 20 anos de idade, que estuda idiomas e já viveu nos Estados Unidos e no Canadá, disposto a ensinar inglês e interessado em aprender português. Foram realizadas três sessões de teletandem por meio dos aplicativos msn

\footnotetext{
${ }^{3}$ Neste artigo, empregamos os termos segunda língua e língua estrangeira com o mesmo sentido, para nos referirmos ao idioma estrangeiro ensinado no ensino formal, neste caso o inglês ou o espanhol.
} 
messenger (duas sessões) e sharedtalk ${ }^{4}$ (uma sessão), utilizando apenas o recurso de bate-papo (chat). Não foram empregados recursos de áudio e vídeo. Os diálogos foram salvos para posterior análise em busca de trechos que evidenciassem as contribuições deste ambiente de aprendizagem à aula convencional.

\section{Aprendizagem de línguas in-tandem: uma experiência}

\subsection{As interações}

As interações ocorreram a distância com ambos os participantes acessando a Internet em sua própria residência. Neste artigo, o participante brasileiro será identificado pelo pseudônimo Eduardo e, o mexicano, pelo pseudônimo Pablo. Eduardo recebeu instruções sobre os princípios do tandem, principalmente sobre o princípio da reciprocidade, despertando sua atenção para a colaboração com a aprendizagem do parceiro. Isso fica explícito no excerto $1 \mathrm{em}$ que Eduardo emprega ambas as línguas, o inglês, língua em que deseja aperfeiçoar-se, e o português, língua que Pablo deseja aprender, para fazer-se entender e auxiliar na compreensão do outro. Abaixo de cada excerto, está a nossa tradução para o português:

\section{(Excerto 1)}

Pablo: what are you doing now? (besides chatting, of course! XD)

Eduardo: hehehe

Eduardo: I was looking 5 people in the sharedtalk

Eduardo: and you? - e você?

Pablo: not alot, just finished of watch a movie

Eduardo: $a h$

Eduardo: what movie? - qual filme?

Pablo:hum.... in spanish: "Locura de amor"

Eduardo: in portuguese:Loucura de AMOR

\footnotetext{
${ }^{4}$ Assim como o site $w w w . s h a r e d t a l k . c o m$, os sites www.livemocha.com $\mathrm{e}$ $w w w$.tandemserver.com são sites gratuitos de tandem em que indivíduos, de qualquer faixa etária, interessados em aprender outro idioma, se cadastram e encontram parceiros compatíveis para iniciar as sessões de tandem.

${ }^{5}$ Os excertos foram transcritos da forma como ocorreram nas interações, portanto formas agramaticais e outras inadequações, tais como minúsculas ao invés de maiúsculas e ortografia errada, por exemplo, foram mantidas.
} 
(Tradução do excerto 1)

Pablo: o que você está fazendo agora? (além de conversar é claro!)

Eduardo: hehehe

Eduardo: eu estava procurando pessoas no sharedtalk)

Eduardo: e você? - e você?

Pablo: não muito, acabei de assistir um filme

Eduardo: ah

Eduardo: qual filme? - qual filme?

Pablo:hum.... em espanhol: "Locura de amor"

Eduardo: em português:Loucura de AMOR

O aluno é inserido numa situação real de comunicação onde ele tem que se fazer entender e entender o parceiro, seu interlocutor. Os participantes têm a oportunidade de desenvolver suas próprias estratégias para que o parceiro o compreenda. No excerto 2, por exemplo, Eduardo levanta uma questão sobre o termo saudade, existente só na língua portuguesa, para saber como Pablo expressa esse conceito em inglês. Eduardo explica que o termo saudade é empregado para expressar a falta que sentimos de alguém querido e, em seguida, pergunta como esse sentimento é expresso nos Estados Unidos. Pablo responde que não tem certeza se há uma palavra específica para esse sentimento, mas pede um exemplo da palavra em uso na língua portuguesa. Eduardo fornece um exemplo agramatical traduzido literalmente para o inglês (I feel your lack ${ }^{6}-\mathrm{Eu}$ sinto sua falta). Finalmente, Pablo encontra a expressão homesickness que se refere à saudade do lar ou do país de origem e faz uma observação gramatical sobre o gênero masculino ( $\mathrm{him}$ ) e feminino (her). O esforço de ambos para explicar e entender o conceito de saudade na língua portuguesa e encontrar um correspondente na língua inglesa indica o desenvolvimento da cooperação no processo de aprendizagem de ambos:

(Excerto 2)

Eduardo: I have a question

Pablo: go ahead!

\footnotetext{
${ }^{6} \mathrm{O}$ termo lack usado pelo participante brasileiro significa "falta, carência de algo" e nunca é usado para referir-se ao sentimento de saudade (LONGMAN, 2000, p. 785).
} 
Aprendizagem de línguas in-tandem: um suporte inovador

Eduardo: in Brazil, when we are feeling lack of somebody, we say the word "saudade"

Eduardo: and in USA?

Eduardo: how are they explained when they feel lack of anybody?

Pablo: I'm not sure there's an specific word. At least, I've never used it, though! gimme a second, there most be a word for that...

Eduardo: $o \mathrm{k}$

Pablo: Ok, let's do this... gimme an example in portuguese where you say "saudade", please

Eduardo: $o k$

Eduardo: I feel your lack

Eduardo: Eu sinto saudades

Eduardo: we used the word saudade for people that are far

Pablo: Oh!!! ok, I get it

Pablo: I miss him or her (depending of the gender)

Pablo: to miss someone, in general terms

Eduardo: huum

Eduardo: $o k$

Pablo: homesicknesses, if you are talking about your country, you know, instead of "I miss my country", "I feel homesicknesses"

(Tradução do excerto 2)

Eduardo: eu tenho uma pergunta

Pablo: prossiga!

Eduardo: No Brasil, quando sentimos falta de alguém, usamos a palavra "saudade".

Eduardo: e nos Estados Unidos

Eduardo: como eles se expressam quando sentem falta de alguém

Pablo: eu não tenho certeza, se há uma palavra específica. Pelo menos eu nunca usei ..... dê-me um segundo, deve haver alguma palavra para isso.

Eduardo: ok

Pablo: Ok, façamos assim... dê-me um exemplo em português onde você usa "saudade", por favor.

Eduardo: ok

Eduardo: eu sinto sua "falta"

Eduardo: Eu sinto saudades

Eduardo: nós usamos a palavra saudade para pessoas que estão longe.

Pablo: Ok, entendi

Pablo: Sinto falta dele ou dela (depende do gênero)

Pablo: perder alguém, geralmente 
Edi Marli da Silva Nunes e Wiliam César Ramos

Eduardo: huum

Eduardo: ok

Pablo: "homesickness", se você estiver falando sobre seu país, em vez de: eu sinto falta do meu país, eu sinto "homesickness".

Nesse processo de cooperação estabelece-se o compromisso de se preparar para as próximas sessões, elaborando material organizado sobre assuntos a serem abordados ou questões linguísticas que apresentaram dúvidas nas sessões anteriores, conforme verificamos no excerto 3 em que Pablo sugere que ambos elaborem uma lista de verbos que desejam aprender:

(Excerto 3)

Pablo: maybe today and I'll be here tomorrow as well

Eduardo: we can talk again?

Pablo: sure!

Pablo: get your list of verbs you wanna learn in english, and I'll make mine!

Eduardo: ah ok

(Tradução do excerto 3)

Pablo: talvez hoje, e amanhã estarei aqui

Eduardo: podemos falar novamente

Pablo: claro!

Pablo: faça sua lista de verbos que você quer aprender em inglês, e eu farei a minha.

Eduardo: ah, ok

Tópicos gramaticais também são abordados nas interações, permitindo que dúvidas não esclarecidas em sala de aula possam ser sanadas nos diálogos com o parceiro. No excerto 4, Eduardo pergunta como se usa o verbo aprender (to learn) e Pablo explica que é a ação de adquirir novos conhecimentos e apresenta a conjugação do verbo:

(Excerto 4)

Eduardo: how i can use the verb to LEARN?

Pablo: I learn, you learn, he learn(s), she learn(s), we learn, they learn.... It is used to express the action of get new knowledge. It's the process you are supposed to do while you are at school $[\ldots]$ 
Aprendizagem de línguas in-tandem: um suporte inovador

Eduardo: for each people verbal we use one form of conjugation

Eduardo: to learn

Eduardo: aprender

Eduardo: I learn - eu aprendo

Eduardo: you learn - tu/você aprendes

Pablo: você it's a formal expression, right?

Eduardo: yes

Eduardo: he/she - ele-ela aprende

[...]

Eduardo: did you find difficult?

Eduardo: I think no

Pablo: nope. I find it very similar to spanish, indeed

(Tradução do excerto 4)

Eduardo: como posso usar o verbo APRENDER?

Pablo: Eu aprendo, você aprende, ele aprende, ela aprende, nós aprendemos, eles aprendem... É usado para expressar a ação de adquirir novos conhecimentos. Este é o processo usado enquanto você está na escola.

$[\ldots]$

Eduardo: para cada pessoa verbal nós usamos uma forma de conjugação

Eduardo: aprender

Eduardo: aprender

Eduardo: eu aprendo - eu aprendo

Eduardo: você aprende - tu/você aprende(s)

Pablo: você é uma expressão formal, certo?

Eduardo: $\operatorname{sim}^{7}$

Eduardo: ele/ela - ele-ela aprende

[...]

Eduardo; você achou difícil?

Eduardo: eu acho que não

Pablo: não. Eu achei bem parecido com o espanhol, pra falar a verdade.

Durante as interações, os temas dos diálogos vão se diversificando. No excerto 5, por exemplo, Pablo pergunta se Eduardo sabe quais são as sete maravilhas naturais e o convida a participar de

\footnotetext{
${ }^{7}$ Informações inadequadas ou imprecisas podem ser retificadas posteriormente pelos próprios participantes a partir de anotações feitas durante as interações.
} 
uma votação on-line para eleger o Rio Amazonas como uma das sete maravilhas:

\section{(Excerto 5)}

Pablo: hey, did you realized that there are new 7 natural wonders?

Eduardo: no

Eduardo: what wonders?hehe

Pablo: hum... let me give you an URL: http://www.new 7 wonders.com Eduardo: $o k$

Pablo: We gotta vote for the amazone river! XD

(Tradução do excerto 5)

Pablo: ei, você viu que há 7 novas maravilhas naturais?

Eduardo: não

Eduardo: quais maravilhas?

Pablo: dê uma olhada em URL: http://www.new7wonders.com

Eduardo: ok

Pablo: Nós podemos votar no rio Amazonas

A análise desses excertos demonstra que o ambiente de aprendizagem in-tandem pode, de fato, complementar a aula convencional, pois permite que o aluno exercite suas habilidades comunicativas, aprimore seus conhecimentos gramaticais, desenvolva estratégias de estudo, tenha acesso a assuntos diversificados não abordados em classe e aprenda outras culturas.

\subsection{O tandem no Ensino Médio: uma proposta}

Segundo Pais (2005, p. 143), “a transição para a sociedade da informação requer estratégias educativas mais audaciosas do que aquelas representadas pelos métodos tradicionais de aprendizagem”. As transformações que ocorrem em todas as áreas da sociedade, em especial na área tecnológica, são refletidas na aprendizagem de uma língua e nos métodos adotados para o seu ensino. $\mathrm{O}$ ambiente de aprendizagem in-tandem insere-se nesse contexto tecnológico e pode complementar as abordagens e estratégias pedagógicas adotadas atualmente.

A nossa proposta é direcionada ao Ensino Médio em função: a) do impacto que a formação proporcionada por esse estágio do Sistema 
Brasileiro de Educação tem no país como um todo; b) do grande número de alunos por sala, que inviabiliza a prática de conversação em classe; c) da meta pedagógica, da disciplina Língua Estrangeira Moderna, de permitir que o aluno descubra as possibilidades de interação com indivíduos de outras culturas (BRASIL, 2003); d) da dificuldade de se atender às necessidades individuais dos alunos em consequência da heterogeneidade de gostos e interesses; e) da orientação exposta nos Parâmetros Curriculares Nacionais do Ensino Médio de que se faça uso das tecnologias de informação em situações relevantes (BRASIL, 2003); f) da falta de oportunidade aos alunos de estarem inseridos em uma situação real de comunicação em língua estrangeira; e g) das teorias de aprendizagem de língua estrangeira que dão suporte à aprendizagem in-tandem.

$\mathrm{O}$ aprendizado de idiomas estrangeiros deve propiciar que o aluno perceba as possibilidades de ampliação de suas interações com outros. Esse aprendizado, contudo, não deve constituir processo de desvinculação cultural; pelo contrário, é reforçador de trocas culturais enriquecedoras e necessárias para a construção da própria identidade. (BRASIL, 2003, p. 97).

Por permitir a confluência de autonomia de aprendizagem, que atende aos interesses individuais dos participantes de intercâmbio sociocultural, que permite um amadurecimento intelectual e atitudinal, de inserção do aluno em uma situação real de comunicação, que possibilita o desenvolvimento de suas habilidades linguísticas, e de sua consonância com as orientações dos Parâmetros Curriculares Nacionais do Ensino Médio, que favorece a sua implementação, a aprendizagem de línguas in-tandem apresenta-se como uma possibilidade de enriquecer o ensino de língua estrangeira no Ensino Médio, complementando a rotina pedagógica das aulas tradicionais.

Entretanto, o sucesso de sua aplicação depende, dentre outros fatores, da infraestrutura oferecida pela instituição de ensino (laboratório de informática devidamente equipado), do empenho e da competência do professor mediador, e do interesse e da disciplina do aluno. A ausência de um desses elementos essenciais tende a inviabilizar a implementação do tandem institucionalizado, seja em 
escolas públicas ou privadas. Os alunos de escolas, que não possuem parceria com escolas estrangeiras ou não dispõem de laboratório de informática, podem realizar as sessões de tandem acessando a Internet de suas casas ou de lan houses, e solicitar assistência do professor quando surgirem dúvidas ou dificuldades.

Assim como ocorre na UNEMAT, na University of Minnesota e em outras instituições de ensino que oferecem aprendizagem de línguas in-tandem, os projetos de tandem institucionalizado não visam e não obtêm a adesão de todos os alunos porque sua adesão depende do interesse do aluno em buscar o aprimoramento de seus conhecimentos, e porque o tandem ainda é pouco conhecido no meio educacional e em outras esferas da sociedade. Esse anonimato pode fazer com que pareça complicado ou ineficiente interagir com essa modalidade de aprendizagem, principalmente quando é exposto que não há a figura do professor e que são os próprios participantes que ensinam e aprendem, a partir dos esforços empreendidos no desenvolvimento de sua própria competência linguística e na colaboração com a aprendizagem do parceiro. Os projetos de tandem institucionalizado não constituem um regulamento, mas uma possibilidade de aprimoramento da formação educacional do corpo discente, oferecida pela instituição.

De acordo com Long (1980, 1983 apud MITCHELL; MYLES, 2004), a aquisição ${ }^{8}$ de uma segunda língua resulta da interação entre dois falantes quando negociam significados (Interaction Hypothesis), seja repetindo ou parafraseando o que foi dito, seja solicitando esclarecimentos. Conforme o autor, esse processo que ocorre entre adultos aprendendo uma segunda língua é semelhante ao de um adulto nativo interagindo com uma criança nativa, ambos se esforçando para compreender e ser compreendidos. A compreensão e a aprendizagem de uma língua também decorrem de aspectos culturais. Segundo Ochs (1988, apud MITCHELL; MYLES (2004), a aquisição do conhecimento linguístico está diretamente vinculada à aquisição do conhecimento sociocultural (Language Socialization). Para a autora, a

\footnotetext{
8 Alguns pesquisadores distinguem aquisição de aprendizagem, sendo o primeiro termo empregado para designar um processo formal, planejado e consciente e o segundo, para definir um processo informal, não-planejado e inconsciente. Como essa distinção ainda é defendida e questionada por teóricos da área de aprendizagem de línguas e não é o foco desta pesquisa, não diferenciaremos um conceito do outro, seguindo a postura metodológica adotada por Mitchell e Myles (2004, p (?)).
} 
organização social da vida cotidiana, valores morais, ideologias e crenças são adquiridos, em grande medida, pela linguagem; a criança constrói seu universo sociocultural interagindo com adultos por meio da linguagem. Isso significa que a aprendizagem de uma segunda língua é simultânea à aprendizagem dos aspectos socioculturais do povo que a tem como língua materna.

A aprendizagem de línguas in-tandem reflete esses princípios interacionistas e sociolinguísticos de aquisição de língua, pois viabiliza o desenvolvimento de competências linguísticas e estratégias de ensino e aprendizagem em situações reais de comunicação, aspecto que transforma os participantes em sujeitos autônomos no processo de aquisição do idioma, e possibilita o intercâmbio cultural, experiência que favorece a aprendizagem da língua e prepara o indivíduo para o mundo globalizado. Além disso, acompanhando as transformações contemporâneas das práticas pedagógicas vigentes, o uso das novas tecnologias com vistas a melhorar a qualidade do ensino é indicado pelos Parâmetros Curriculares Nacionais do Ensino Médio. Portanto, entendemos que a aprendizagem de línguas in-tandem pode atuar como um complemento às aulas convencionais do Ensino Médio.

\section{Considerações finais}

As novas tecnologias utilizadas no ensino de língua estrangeira permitem uma abordagem pedagógica inovadora, mais atraente e mais dinâmica. Tendo em vista que as aulas convencionais de língua estrangeira no Ensino Médio podem ser aprimoradas por meio das novas tecnologias, este trabalho apresenta as contribuições que o ambiente de aprendizagem de línguas in-tandem pode trazer para o processo de aprendizagem e sugere sua possível inclusão no currículo escolar (tandem institucionalizado) como mais uma possibilidade de enriquecer a aula tradicional.

A experiência realizada com o participante brasileiro e o participante mexicano demonstrou que os benefícios à aprendizagem do aluno, tais como o aprimoramento de suas habilidades comunicativas, a ampliação de conhecimentos gramaticais aprendidos e o desenvolvimento de estratégias de estudo, além do acesso a outras culturas e assuntos diversificados não abordados em classe podem ser 
obtidos por meio da aprendizagem in-tandem. Ela pode proporcionar benefícios tanto para o aluno quanto para o professor. Para o aluno representa a oportunidade de aprender a língua não só por meio de explicações sistematizadas, mas também empregando-a numa situação real de comunicação. Para o professor representa a possibilidade de diversificar sua aula e seu papel, de ser mediador em vez de controlador, de estimular o interesse de seus alunos e de ajudá-los a tornarem-se responsáveis pela sua própria aprendizagem.

Toda inovação, em qualquer área da sociedade, ocorre de forma gradativa, conforme velhos hábitos vão sendo abandonados e novas práticas passam a ser adotadas, à medida que os benefícios do novo são divulgados por seus adeptos e percebidos por contemporâneos. A mudança é um longo processo e demanda planejamento, mas toda mudança nasce a partir de questionamentos que se transformam em pesquisas que, por sua vez, sugerem possibilidades de melhoria, e é isso que procuramos realizar neste artigo: apontar uma possibilidade de enriquecer a aprendizagem de língua estrangeira dos alunos do Ensino Médio, permitindo que pratiquem o idioma em uma situação real de comunicação, diferente da vivenciada em sala de aula.

\section{Referências}

ALMEIDA, Fernando. J.; FONSECA JUNIOR, Fernando. M. Projetos e ambientes inovadores. Secretaria de Educação a Distância. Brasília: Ministério da Educação, SEED, 2000.

BRAMMERTS, Helmut. Autonomous language learning tandem. In LEWIS, Tim.; WALKER, Leslie. (Org.). Autonomous language learning in-tandem. Sheffield, UK: Academy Electronic Publications, 2003. p. 27-36.

BRAGA, Junia C. F. Aprendizagem de línguas em regime de tandem via e-mail: colaboração, autonomia e estratégias sociais e de compensação. 2004. 152 p. Dissertação (mestrado em: Linguística Aplicada) - Universidade Federal de Minas Gerais, Faculdade de Letras, Belo Horizonte, 2004. 
Aprendizagem de línguas in-tandem: um suporte inovador

BRASIL. SECRETARIA DE EDUCAÇÃO BÁSICA. PCN+Ensino Médio: orientações educacionais complementares aos parâmetros curriculares nacionais. 2003. Disponível em: <http://portal.mec.gov.br/seb/arquivos/pdf/linguagens02.pdf>. Acesso em: 08 jan. 2012.

CARBONELL, Jaume. A aventura de inovar: a mudança na escola. Tradução de Fátima Murad. Porto Alegre: Artmed Editora, 2002.

LARSEN-FREEMAN, Diane. Techniques and principles in language teaching. 2 ed. Oxford: Oxford, 2004.

LITTLE, David. Tandem language learning and learner autonomy. In: LEWIS, Tim; WALKER, Leslie. (Orgs.). Autonomous language learning in-tandem. Sheffield: Academy Electronic Publications, 2003. p. 37-44.

LONGMAN dictionary of contemporary English. Essex: Longman, 2000.

MARTINS, Jorge S. Projetos de pesquisa: estratégias de ensino e aprendizagem em sala de aula. Campinas: Armazém do Ipê, 2005.

MITCHELL, Rosamond; MYLES, Florence. Second language learning theories. 2a ed. Londres: Hodder Education, 2004.

MORAN, José M.; MASETTO, Marcos T.; BEHRENS, Marilda. A. Novas tecnologias e mediação pedagógica. 11. ed. Campinas: Papirus, 2000.

PAIS, Luiz. C. Educação escolar e as tecnologias da informática. Belo Horizonte: Autêntica, 2005.

RAMOS, Wiliam C.; BARBOSA, Maria S. P. R. A. Aprendizagem de línguas in-tandem: quando o aprendiz exerce o papel de mediador. Estudos Linguísticos, São Paulo, v. 38, n. 2, p. 183-195, maio-ago. 2009.

Disponível

em: 
<http://www.gel.org.br/estudoslinguisticos/volumes/38/EL_V38N2_15 .pdf $>$. Acesso em: 15 maio 2010.

UNEMAT UNIVERSIDADE DO ESTADO DE MATO GROSSO. Alto Araguaia: Unemat faz parceria com Universidade de Minnesota (EUA). 2011. Disponível em: <http://www.novoportal.unemat.br/?pg=noticia/6275/Unemat $\% 20 \mathrm{faz} \%$ 20parceria\%20com\%20Universidade $\% 20 \mathrm{de} \% 20$ Minnesota\%20(EUA) >. Acesso em 08 jan. 2012.

Alto Araguaia: Unemat abre inscrições para prática de tandem via chat. 2009. Disponível em: <http://www.novoportal.unemat.br/?pg=noticia/4911/Unemat\%20abre $\% 20$ inscri\%E7\%F5es\%20para\%20Pr\%E1tica\%20de\%20Tandem\%20 via\%20Chat>. Acesso em 08 jan. 2012.

Recebido em: 17 de maio de 2010 Aceito em: 26 de agosto de 2011

Title: Language learning in tandem: an innovative tool for traditional English learning 
Aprendizagem de línguas in-tandem: um suporte inovador 